\title{
Noise properties and cascadability of SOA-EA regenerators
}

\author{
Öhman, Filip; Bischoff, Svend; Tromborg, Bjarne; Mørk, Jesper
}

Published in:

2002 IEEE/LEOS Annual Meeting Conference Proceedings

Publication date:

2002

Document Version

Publisher's PDF, also known as Version of record

Link back to DTU Orbit

Citation (APA):

Öhman, F., Bischoff, S., Tromborg, B., \& Mørk, J. (2002). Noise properties and cascadability of SOA-EA regenerators. In 2002 IEEE/LEOS Annual Meeting Conference Proceedings (Vol. 2). IEEE.

\section{General rights}

Copyright and moral rights for the publications made accessible in the public portal are retained by the authors and/or other copyright owners and it is a condition of accessing publications that users recognise and abide by the legal requirements associated with these rights.

- Users may download and print one copy of any publication from the public portal for the purpose of private study or research.

- You may not further distribute the material or use it for any profit-making activity or commercial gain

- You may freely distribute the URL identifying the publication in the public portal

If you believe that this document breaches copyright please contact us providing details, and we will remove access to the work immediately and investigate your claim. 
ThCC4

$17: 15-17: 30$

\title{
NOISE PROPERTIES AND CASCADABILITY OF SOA-EA REGENERATORS
}

Filip Öhman, Svend Bischoff, Bjarne Tromborg and Jesper Mørk

COM, Technical University of Denmark, Build. 345v, DK-2800 Kgs. Lyngby, Denmark (fo@com.dtu.dk)

\begin{abstract}
We suggest and analyse a new device containing concatenated pairs of SOAs and EAs. The device has regenerative properties and improves the cascadability of optical fibre links.
\end{abstract}

\section{Introduction}

It has been shown experimentally and theoretically that the incorporation of a saturable absorber in a fiber link containing a semiconductor optical amplifier (SOA) can significantly improve the transmission performance by suppressing low-intensity noise [1,2]. We propose here a novel device, which contains a cascade of SOAs and electro absorbers (EA); see Fig. 1. A detailed analysis of the device is performed, which shows that substantial improvements in the cascadability of fibre-amplifier links can be obtained, i.e. the device has regenerative properties. We have in mind a monolithically integrated device, with forward and reverse biased waveguide sections. This is similar to a mode-locked laser design, and the device performs signal shaping and pedestal suppression similar to the shaping of pulses circulating in a mode-locked laser.

\section{The model}

We model the device behaviour using the standard rate equation model of ref. [3] for an SOA, extended to include internal loss. The saturable EA is modelled in. a similar way by applying an effective carrier lifetime incorporating carrier sweep-out. As shown in figure 1 the model includes a fiber span in the form of a fixed loss between the modules.

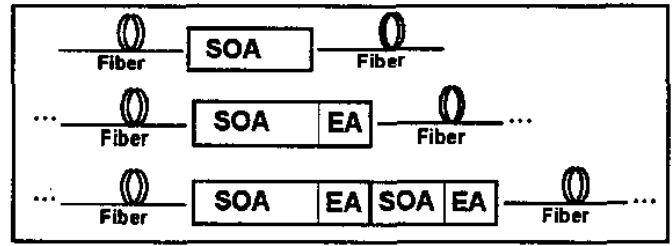

Fig. 1. Schematic of the simulated modules. The small-signal gain for the SOAs is $31 \mathrm{~dB}$ for the first, and $19 \mathrm{~dB}$ for the following ones in the device. The corresponding small-signal absorption in the EAs is 20 and $27 \mathrm{~dB}$. The fixed internal loss is $2000 \mathrm{~m}^{-1}$ for both SOAS and EAs, and the ratio between the saturation power of the EAs and the SOAs is 0.25 .

The noise added by the SOAs was modelled using standard expressions for the signal-spontaneous beat noise in an amplifier; see for example ref. [4], taking into account gain saturation and the corresponding increase of the population inversion factor. In all cases the signal was kept at a level where other noise contributions can be neglected.

\section{Results}

The model has been solved under quasi-cw operation for different configurations: single SOAs with different gain, different number of SOA-EA pairs and finally an ideal linear amplifier with the same noise figure as the short single SOA. The resulting static transfer functions are shown in figure 2. The transfer functions include the fibre loss, which has been chosen to precisely compensate the device gain at the power level for the logical "1", i.e. at about $0.16 \mathrm{~mW}$ where the output power from one span is equal to the input power. The total gain of the modules at this operating point is $18.6 \mathrm{~dB}$ for the long SOA and $10.3 \mathrm{~dB}$ for the SOA-EA pairs, the short SOA and the linear amplifier.

The non-linear transfer functions result from the saturation of the EA absorption and the SOA gain. The small signal absorption of the EAs is high and suppresses the low intensity noise, however it is bleached at higher powers, if the saturation power of the SOA is high enough. At even higher powers the SOA saturates and gives a flat transfer function that redistribute the noise at the "1"-level. Since the device operates in saturation the response time needs to be fast compared to the bit rate; justifying the quasi-cw approach for evaluating the BER-penalties from ASE in the next section.

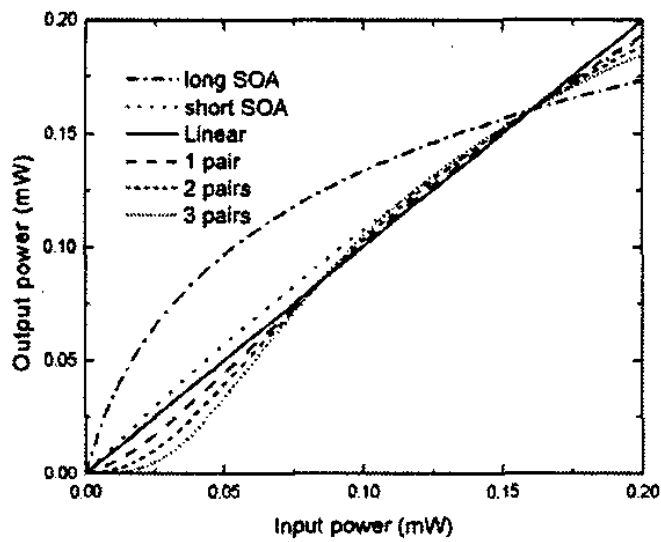

Fig. 2. Transfer functions for one, two and three SOAEA pairs as well as for the single SOAs and a linear function 
The noise properties were investigated by calculating the noise figures of the different devices. As shown in figure 3 the noise figure only increases slightly as more SOA-EA pairs are added, which would imply that the sharper transfer function could indeed be used for stronger noise redistribution and regeneration without adding too much additional noise. However, the overall gain of the device is reduced by the EA, so the performance of the different devices has to be compared for the same total link loss. The noise figure for the long SOA is the same as for one SOA-EA pair since the absorption of the EAs is assumed to be linear in the noise figure calculation.

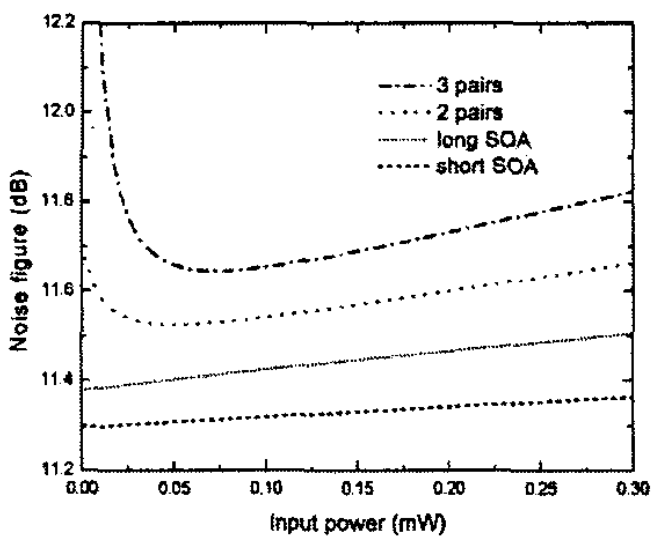

Fig. 3. The noise figures for the investigated configurations, including an input coupling loss of $3 d B$.

\section{BER of a cascade}

In order to investigate the Bit-Error-Rate (BER) behaviour of a system of concatenated amplifiers and fiber links the model presented in $[5,6]$ was used. The probability density functions for marks and spaces are assumed known initially and Gaussian noise, representing spontaneous emission for the SOAs, is then added for each link. Probability transfer matrices represent the noise redistribution of the non-linear transfer functions, and concatenation is done by matrix multiplication. The result for an input signal with a signal to noise ratio for the " 1 "-level of $25.5 \mathrm{~dB}$ and the same noise variance at the " 0 "-level is shown in figure 4. The BER is plotted versus the total link loss for one, two and three SOA-EA pairs as well as for the long and short SOA and for the linear amplifier with no noise redistribution. For few regenerators the noise of the input signal dominates but as more ASE accumulates from several regenerators the BER increases from the added noise. For many regenerators the BER only increases slowly, similar to the linear BER degradation with number of regenerators that is obtained for an ideal step function
[5]. It is also seen that the sharper transfer functions do indeed improve the performance of the system. Also the additional SOA-EA pairs further decrease the BER substantially.

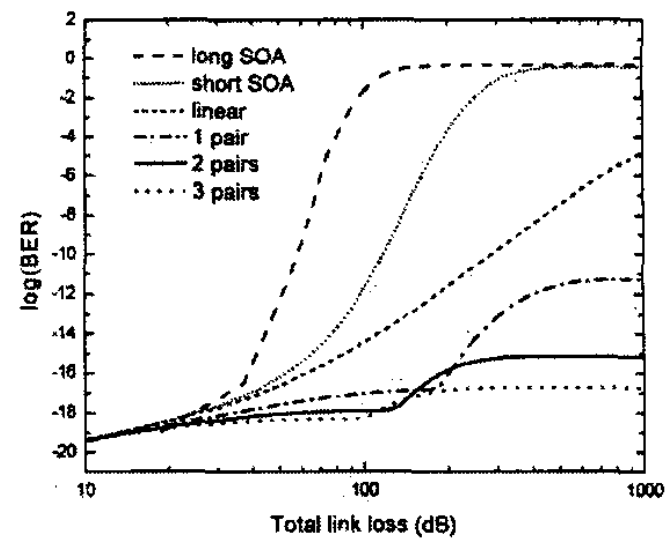

Fig. 4. The BER as a function of total link loss, which is equal to the number of regenerators times their gain.

Jitter and dispersion effects have not been included in the analysis (2R-regeneration). However, it may also be mentioned that for return-to-zero signals the cascade of SOA-EA pairs leads to significant pulse shortening, similar to the intra cavity pulse shaping in mode-locked lasers.

\section{Conclusions}

We have investigated the noise properties and noise redistribution in cascaded SOA-EA regenerators. The calculations show that the noise suppression of concatenated SOA-EA pairs improves the cascadability although the noise figure is somewhat higher and the gain lower than for a single SOA. In particular we have shown that in a cascade of many amplifiers the BER is greatly improved by the suggested device.

\section{References}

1 C. Knöll et al. Opt. Commun., vol. 187 (2001), 141153.

2 Z. Bakonyi et al. IEEE Photon. Technol. Lett., vol. 12 (2000), 570-572.

3 G. P. Agrawal et al. IEEE J. Quantum Electron., vol. 25 (1989), 2297-2306.

4 N. A. Olsson J. Lightwave Technol., vol. 7 (1989), 1071-1082.

5 P. Öhlén et al. IEEE Photon. Technol. Lett., vol. 9 (1997), 1011-1013.

6 S. Bischoff et al., IEEE Photon. Technol. Lett., vol. 14 (2002), 33-35. 